\title{
Movimientos asociativos en la masonería española en Filipinas
}

\section{Associative movements in Spanish Freemasonry in the Philippines}

Susana Cuartero Escobés

Universidad de Zaragoza, España

scescobes@gmail.com

Recepción: 18 de febrero de 2020/Aceptación: 7 de abril de 2020

doi: https://doi.org/10.15517/rehmlac.v12i1-2.40801

\section{Palabras clave}

Filipinas; masonería española; Katipunan; José Rizal; Miguel Morayta.

\section{Keywords}

Philippines; Spanish Freemasonry; Katipunan; José Rizal; Miguel Morayta.

\section{Resumen}

A partir de 188o España no fue capaz de manejar el Pacífico español debido a su caduco sistema administrativo. La brecha entre peninsulares y nativos se fue agrandando y entre ellos se situó una emergente élite de filipinos educados en centros españoles, con una cuidada ilustración, que comenzó a tener ideas propias. La estancia de varios de ellos en la Península les brindó la oportunidad de agruparse en asociaciones e instituciones como la masonería y alrededor de destacados personajes como José Rizal o Miguel Morayta, con el único fin de dar a conocer la problemática filipina y conseguir reformas modernizadoras.

\section{Abstract}

From the 188 os, Spain was unable to manage the situation in the Spanish Pacific due to its obsolete administrative system. An emerging elite of Filipinos stood in the increasingly widening gap between peninsular people and native people. This group of Filipinos educated in Spanish centers began to have ideas of their own. The stay of several Filipinos in Spain gave them the opportunity to group in many associations and institutions such as Freemasonry and around prominent figures such as José Rizal or Miguel Morayta, they only had one purpose: to announce the Philippine problem and getting modernizing reforms. 


\section{Introducción}

La asociación es el mecanismo que explica cualquier actividad del ser humano, de modo que, los movimientos asociativos son aquellos que manifiestan la formación de grupos de individuos en función de diferentes intereses. La masonería como es sabido se desarrolló en la Edad Media ligada a las asociaciones gremiales relacionadas con el arte de la construcción, es decir, que ya desde sus orígenes, se encuentra inmersa en este tipo de agrupaciones que, además, cambiaron y evolucionaron a lo largo del tiempo.

En este trabajo pretendemos aproximarnos a la creación del gran movimiento asociativo que es la masonería, en un espacio que se desplaza del área de Latinoamérica y el Caribe al Pacífico español, territorio incluido en el Virreinato de Nueva España, que en 2019 conmemoró el V Centenario de la Primera Vuelta al Mundo. Nos ubicaremos en Filipinas, ese lugar tan desconocido como olvidado en la historiografía española.

MAPA DE 1589 DEL OCÉANO PACÍFICO, DE ABRAHAM ORTELIUS, CON LA NAO VICTORIA

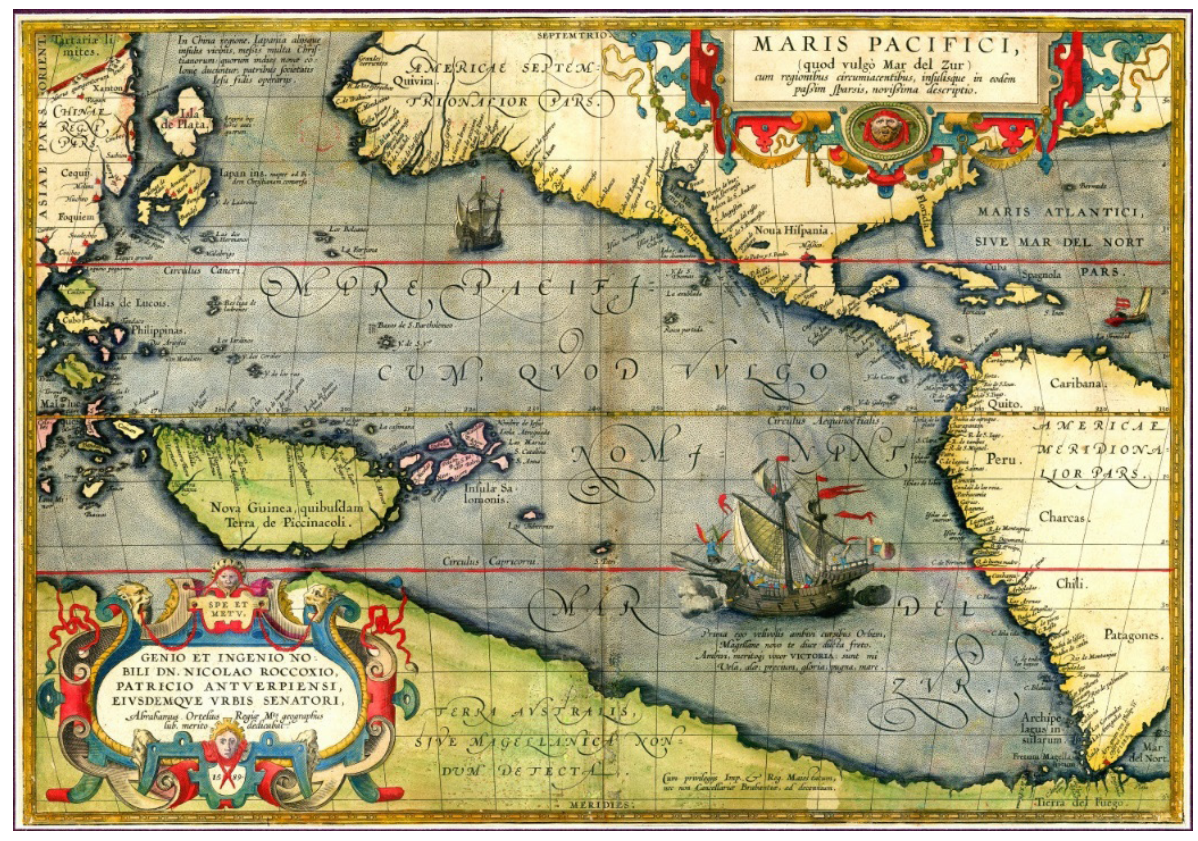

Fuente: Real Instituto Elcano.

\section{Situación en el Pacífico español}

Los territorios que compusieron el Pacífico español, las islas Filipinas y todas las posesiones de la micronesia española, fueron gobernados desde el Virreinato de Nueva España, con capital en México, hasta la independencia de América en 1821. A partir de ese momento, las comunicaciones, suministros y recursos de cualquier tipo se vieron afectados, ya que pasaron a depender directamente de la lejana capital de España. A esta dificultad se unió el hecho de que en las Constituciones de 1837 y de 1845 quedó establecido que las provincias de Ultramar pasaban a ser administradas por leyes especiales, desapareciendo la igualdad de todos los españoles que había proclamado la Constitución de Cádiz en 1812. 
La apertura del canal de Suez en 1869 fortaleció el vínculo comercial permitiendo un incipiente desarrollo económico, pero los asuntos relativos a cultura, política y educación se complicaron debido al choque que supuso la llegada de nuevas y modernizadoras ideas a un territorio dominado por las órdenes religiosas¹.

Además, en este tiempo, se recrudecieron los ataques extranjeros a las islas y comenzaron a ser frecuentes las revueltas indígenas ${ }^{2}$ y criollas, como la de Andrés Novales, en 18213; la insurrección en Tayabas en 1841, sofocada por el general Oraá y que acabó con la ejecución de su cabecilla, Apolinario de la Cruz o, la mucho más conocida, por su repercusión posterior, de Cavite en 1872.

La revuelta de Cavite fue la excusa perfecta para detener, procesar y desterrar o ejecutar a todos aquellos elementos que pudieran resultar incómodos para el gobernador general y las órdenes religiosas. Tras la dura represión por la algarada caviteña ${ }^{4}$ (deportaciones, detenciones, condenas a muerte), un importante grupo de filipinos comprometidos con el reformismo se vio en la obligación de exilarse a otras colonias vecinas, sobre todo a Hong Kong, Singapur y Macao, que pasaron a convertirse en importantes focos de agitación laborantista, en los que circulaban confidencias e informes reservados relativos a imaginarias juntas revolucionarias y a presuntos planes desestabilizadores apoyados por potencias extranjeras de la zona.

En la década de 1880 la situación internacional se fue complicando cada vez más y el Pacífico español comenzó a ser un lugar de conflictos debido a los intereses de las nuevas potencias hegemónicas respecto a las posesiones españolas, como se manifestaría tras el Tratado de París en 1898.

Tras la mediación del Vaticano, el 17 de diciembre de 1885, Alemania devolvió Carolinas y Palaos a Españaร. Unos años más tarde encontramos a Japón «ignorante» de que todo el Pacífico tenía dueño, buscando islas para expandirse. Comenzó con la anexión de las tres islas volcánicas Sulphur, San Alejandro y San Agustín, próximas a Marianas. En 1892, el vizconde Enomotto, ministro de Negocios Extranjeros de Japón, dejó caer la noticia de que el archipiélago de Nuevas Hébridas podría ser ocupado en breve, hecho que no consintieron Francia y Gran Bretaña que poseían Nueva Caledonia y Fidji, respectivamente, en aquella parte de la Polinesia.

Además de estos incidentes diplomáticos, se sabe que mediante la compra masiva de tierras en algunas islas, Alemania y Gran Bretaña intentaron hacerse con ellas, cosa que no fue

$1 \quad$ En realidad, la apertura del Canal de Suez facilitó todo tipo de comunicaciones y relaciones con extremo oriente. En los albores de la revuelta de 1896, gracias a este paso, el viaje de las tropas españolas duraba unos 28 días; embarcaban en Barcelona y, cruzando el Mediterráneo llagaban a Port Said (Egipto). Atravesaban el Canal y se dirigían hacia Adén, en Yemen y de ahí, vía Singapur, a Manila.

2 Los principales focos insurreccionales se dieron en Mindanao y las Bisayas, ambas próximas a las bases de los piratas joloanos, malayos y moros juramentados, especialmente violentos, que depredaban a sus anchas por los mares del sur.

3 Andrés Novales, capitán de milicia de origen filipino, organizó una revuelta capturando varios edificios de Intramuros y consiguiendo el apoyo de la población.

4 Recordemos que el motín cuartelero se saldó con la detención de sesenta y una personas De ellas cuarenta y una fueron condenadas a muerte aunque, finalmente, veintiocho vieron sus penas conmutadas por deportaciones de varios años, mientras que la ejecución de los otros trece, nueve en Manila y cuatro en Cavite (los tres presbíteros filipinos: Mariano Gómez, Jacinto Zamora y José Burgos, y el seglar Francisco Zaldúa) se llevó a cabo para que sirviera de escarmiento.

5 El Tratado Hispano-Alemán de Madrid de 1899 concluyó la venta a Alemania de las islas Marianas, excepto Guam, Carolinas y Palaos. 
posible porque eran propiedad del rey de España y, por lo tanto, inalienables. Otro medio para desestabilizar el orden fue provocar pequeñas revueltas y disturbios repartiendo armas a los nativos, hechos que se dieron en la zona de las Bisayas.

Un auténtico maremágnum político, diplomático y de intereses cruzados fue el Pacífico durante el último cuarto de siglo del XIX. España se encontraba en medio, rodeada por todos (Estados Unidos, Gran Bretaña, Francia, Alemania y Japón), sabedora de que sus posesiones eran codiciadas y por lo tanto expectante en el concierto internacional, pero, a la vez, incapaz de manejar una situación tan comprometida debido a su obsoleto y caduco modo de colonizar e incluso de gobernar.

\section{Orígenes de la masonería española en Filipinas}

La vulnerabilidad de un territorio tan disperso y alejado de la Madre Patria tuvo como consecuencia el incremento de efectivos militares, así como la creación, en 1830, de la figura del gobernador de Filipinas, cargo que se fusionó con el de capitán general. Era, en fin, un militar, a quien se le suponía una persona resuelta, con dotes de mando y capacidad para organizar y repeler cualquier tipo de injerencia externa o de revuelta interna. Sin embargo, fueron contadas las ocasiones en las que pudo actuar sin contar con la presión y la influencia de las órdenes religiosas.

Hacia la década de 1870 se intentaron llevar a cabo reformas modernizadoras que, finalmente, quedaron reducidas a un programa de medidas de índole económico más que social. Dichas medidas propiciaron que la colonia se convirtiera en un territorio rentable para el fisco y para los empresarios que querían probar o incrementar su fortuna. Pese a los aparentes esfuerzos, la realidad era la que era y tanto las autoridades locales como el gobierno del país se mostraron incapaces de mediar para solucionar el creciente descontento de las clases bajas filipinas, en su mayor parte dedicadas a labores rurales y de servicio doméstico. El resultado fue un orden profundamente jerarquizado y dividido entre peninsulares y nativos.

Entre ambos grupos se situó una emergente élite de filipinos educados en centros españoles y cultivados en Europa, que comenzó a tener ideas propias ${ }^{6}$. Fue, precisamente, el interés y el respeto de esta clase por la cultura española lo que facilitó la expansión de las tradiciones durante un largo período de tiempo. Pero esa aura de prestigio hacia lo español se fue tornando en resentimiento, toda vez que el gobierno de la metrópoli no supo canalizar las aspiraciones de una élite criolla que había sido excluida hasta de tener representación en las Cortes. Desde este momento, la lucha por recuperar el estatus perdido a golpe de decreto se convirtió en la máxima aspiración de los intelectuales filipinos que concentrarían sus esfuerzos en lograr ser, nuevamente, una provincia.

En este contexto se sitúan los orígenes de la masonería española en Filipinas. En relación con la Península es un comienzo tardío y del que se tienen muy pocos detalles. Se barajan lu-

$6 \quad$ Hasta la Revolución de 1896 solo los criollos, la élite ilustrada que hablaba castellano aunque hubiera nacido en Filipinas, eran considerados como filipinos por las autoridades españolas. El resto, eran "indios". 
gares, personajes y fechas, pero no hay fuentes verosímiles que lo avalen.

La información fiable relativa a estos orígenes no se remonta más allá de 1873. La primera obediencia que se estableció fue el GODE, que el 19 de enero de 1873 constituyó un triángulo de Caballeros Rosa Cruz, para poder admitir a profanos e iniciarlos, no habiendo hasta esa fecha ninguna logia regular constituida en suelo filipino?

Las escisiones pugnas y diferencias en el seno de las obediencias españolas tuvieron fiel reflejo en las islas, de modo que es difícil desligar el desarrollo de la masonería en Filipinas de lo que ocurrió en la Península. Adoleció de protagonismos personales, irregularidades y anomalías que se tradujeron en un conglomerado de individuos que se calificaban de masones, pero no actuaban como tales.

La estructura administrativa y social impuesta en las islas tampoco facilitaba las relaciones ni entre personas ni, mucho menos, entre grupos. Además de la importante jerarquización, la mayoría de las logias contaba entre sus filas con un nutrido grupo de empleados civiles y militares a los que se dispersaba con frecuentes cambios de destino, imposibilitando las reuniones. Esto demuestra que la masonería, aunque se prefiguraba como la fuerza capaz de aunar los intereses de todos los elementos dispersos, no llegó a tener ni la influencia ni el poder que la historiografía tradicional le ha atribuido.

A lo largo de casi dos décadas, entre 1870 y 1889, la masonería española realizó varios e infructuosos intentos por asentarse y consolidarse en Filipinas. Tuvieron presencia las cinco obediencias preponderantes de la península, con la misma secuencia temporal que vivieron en España: Gran Oriente de España (GODE), Gran Oriente de España, presidido por Juan Antonio Pérez (GODE Pérez), Gran Oriente Nacional de España (GONE), Gran Oriente Español (GOE) y Gran Logia Simbólica Española (GLSE) ${ }^{8}$. De todos ellos tan solo uno, el GOE, fue capaz de crecer, desarrollarse en torno a un poder fuerte, el de su fundador Miguel Morayta, y conseguir una hegemonía masónica tan sólida que superó la crisis finisecular.

\section{La masonería como movimiento asociativo global: actividades en la Península}

La frustración y la impotencia de la élite filipina ante las injusticias de la Administración, abrieron un nuevo frente de batalla más cerca del gobierno peninsular, en la creencia de que podría ser más eficaz. En las décadas de 1880 y 1890, las actividades de la colonia filipina, principalmente charlas, conferencias y reuniones, se iban a desarrollar entre Madrid y Barcelona. Necesitaban visibilidad y para ello intentaron recabar el mayor número de apoyos de políticos, intelectuales y de todos aquellos sectores de la sociedad que se sintieran vinculados y unidos a Filipinas. También se publicitaron mediante la sucesiva creación de instituciones, asociaciones y órganos de difusión que fueron, poco a poco, radicalizando sus posturas, sus demandas

$7 \quad$ Este dato es importante por cuanto en el siglo XX fue uno de los argumentos empleados para defender las posesiones ultramarinas ante el enfrentamiento con la masonería norteamericana por cuestiones de jurisdicción territorial.

8 José Antonio Ferrer Benimeli, "Implantación de logias y distribución geográfico-histórica de la masonería española", en La masonería en la España del siglo XIX, coord. Ferrer Benimeli (Valladolid: CEHME, 1987), tomo I, 57-216. 
y sus actuaciones de tal modo que aquello que comenzó como una petición asimilista-reformista, concluyó con la creación de una sociedad secreta independentista, el Katipunan.

El ascenso de mestizos y criollos, de origen filipino, castellanoparlantes, con base económica independiente y una cuidada ilustración, unido al triunfo de los ideales de la Revolución de 1868 y al apoyo incondicional de los más destacados intelectuales filipinos, impulsaron ese paso adelante que los llevó a fijar su meta en la obtención de una serie de reformas.

Con objeto de organizar y sistematizar dichas demandas, cobró vida lo que se dio en llamar el movimiento de La Propaganda, cuyo objetivo principal no era otro que dar a conocer la situación del archipiélago en España. Sus principales postulados eran la representación en las Cortes, la limitación del poder y los privilegios de las órdenes religiosas y la reforma de todo el aparato administrativo y burocrático; es decir, asimilismo y modernización.

Establecer una fecha de fundación y unos creadores para La Propaganda es complicado, puesto que el movimiento fue tomando cuerpo con el transcurso del tiempo y los acontecimientos. No obstante, su inicio se suele hacer coincidir con la llegada a España de José Rizal en $1882^{9}$. No debemos calificar este movimiento como político puesto que carecía de programa y de politólogos; era algo mucho más indefinido que ocupaba principalmente a estudiantes, artistas, intelectuales, escritores..., un movimiento en la línea del nacionalismo cultural, aunque posteriormente evolucionara a otro tipo de asociaciones y organizaciones que sí tuvieron cariz político. Es por ello que tampoco podemos fijar su conclusión puesto que, en realidad, no desapareció, sino que se transformó.

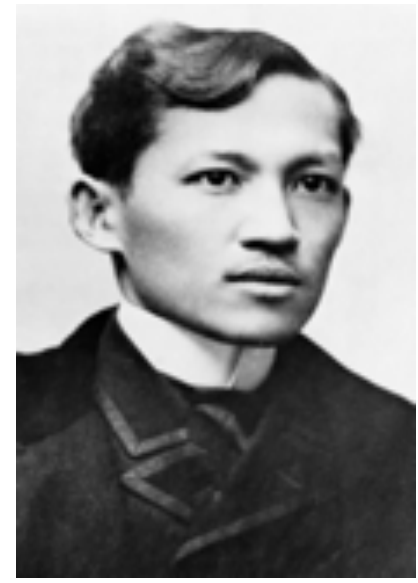

José Rizal

Por estas fechas, mediada la década de 1880 , entre 1885 y 1889 , se aprecia una importante afiliación a la masonería española de la colonia estudiantil filipina afincada en la Península, a diferencia de lo que ocurriera en las propias islas, en donde la barrera racial sí fue un obstáculo. ${ }^{10}$ La masonería española en Filipinas era una institución netamente europea, tendencia que comenzó a cambiar en la segunda mitad de los años 1880 cuando se decidió admitir a todos aquellos indios y mestizos que "supieran leer y escribir y tuvieran una posición responsable, suponiendo que amaran a España y tuvieran una religión definida”.

$9 \quad$ Leoncio Cabrero fija su inicio en un artículo de Gregorio Sanciano y Gosón aparecido en 1881 en el periódico Progreso de Filipinas que explicaba la diferencia entre lo que decía el Gobierno y lo que realmente ocurría en Filipinas. Leoncio Cabrero, "La actitud de la masonería ante la independencia de Filipinas", en Masonería española y América, coord. Ferrer Benimeli (Zaragoza: CEHME, 1993), tomo II, 1097-1105.

10 Igual de complejo que determinar el origen de la masonería en las islas, es saber cuándo ingresaron en la institución los primeros filipinos nativos. La historiografía suele citar a Jacobo Zobel y a José Felipe del Pan, lo cual no deja de ser un error pues el primero era mestizo y el segundo español. La información aportada por los cuadros lógicos nos confirma que entre 1873 y 1889 la presencia de nativos en las logias españolas en Filipinas era nula, mientras que la de mestizos y criollos era puntual y escasa. De esos treinta y tres, diez eran cubanos, dos puertorriqueños, cuatro filipinos y uno de Martinica. Archivo Histórico Nacional Salamanca (AHNS), Leg. 736-A-11. Los cuatro filipinos eran: Rafael Del Pan, Ricardo Ayllón, Evaristo Aguirre y Julio Llorente. Los dos últimos, estudiantes y amigos de Rizal. 
En 1886 encontramos a dos filipinos, Rafael Del Pan y Ricardo Ayllón, afiliados a la logia Solidaridad no. 359 de Madrid, perteneciente al GODE. A lo largo de ese año fueron iniciados y afiliados más estudiantes de Cuba y Puerto Rico, hasta un total de 33 miembros activos en octubre de $1886^{11}$. Después de atravesar una crisis interna, al año siguiente, en un cuadro lógico fechado el 10 de mayo de 1887, encontramos tan solo a 17 miembros, diez cubanos y un filipino, Graciano López Jaena, simbólico Bolívar, grado 3.

Como la logia no parecía encauzar sus trabajos, se celebró una reunión en la que se planteó la fusión con otros talleres entre los que figuraba la logia Hijos del Trabajo, de la que era venerable Miguel Morayta. La propuesta fue aprobada y la Solidaridad no. 359 dejó de existir.

Carecemos de datos que nos informen de más detalles, pero todo indica que esta logia fue la rampa de lanzamiento de la colonia filipina en Madrid hacia la masonería y que Morayta se perfila como padrino-tutor de este grupo y, por lo tanto, de sus intereses.

El siguiente episodio de los filipinos en la masonería española ocurrió dos años después, en 1889. El 2 de abril de ese año, reunido en Barcelona, en la Rambla de Canaletas no. 2, $3^{\circ}$, un grupo de masones decidieron organizar una nueva logia casi exclusivamente de filipinos y solicitar la carta constitutiva al recién creado GOE, presidido por Morayta. La nueva entidad así formada era la logia Revolución, registrada con el no. $65^{12}$.

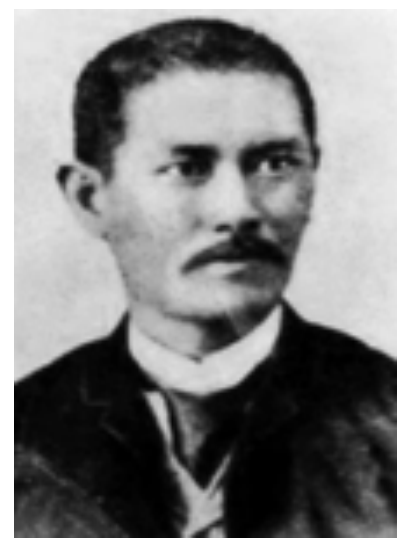

Graciano López Jaena

López Jaena dimitió como Venerable de la Revolución no. 65 el 26 de noviembre de 1889 y, pocos días después, el 8 de diciembre, lo encontramos en Madrid celebrando una reunión preparatoria para reorganizar la logia Solidaridad, que fue admitida en la federación del GOE el 14 de diciembre de 1889 con el no. $53^{13}$, y es en esta logia Solidaridad no. 53 de Madrid en la única que figura José Rizal como miembro activo.

La estructura interna de la masonería peninsular estaba consiguiendo aglutinar y cohesionar a la colonia filipina permitiéndole organizarse y coordinar acciones tendentes a establecer un orden de actuación. Las reuniones de la Solidaridad se convirtieron en verdaderos foros de debate sobre la problemática filipina mediante charlas y conferencias de algunos de sus integrantes ${ }^{14}$, aunque también cabe advertir una cierta utilización de las reuniones para recabar apoyos políticos sobre los que asentar sus aspiraciones nacionalistas.

11 De esos treinta y tres, diez eran cubanos, dos puertorriqueños, cuatro filipinos y uno de Martinica. AHNS, Leg. 736-A-11. Los cuatro filipinos eran: Rafael Del Pan, Ricardo Ayllón, Evaristo Aguirre y Julio Llorente. Los dos últimos, estudiantes y amigos de Rizal.

12 Sobre esta logia ver: Pere Sánchez Ferré, "La masonería española y el conflicto colonial filipino", en La Masonería en la España del siglo XIX, tomo II, 481-496.

13 Sobre este taller: Manuel Adán Guanter, "Una logia de filipinos en Madrid: Solidaridad no. 53 (1889-1895)", en La Masonería en la España del siglo XIX, tomo II, 471-479.

14 En la documentación conservada de la logia no hemos encontrado ningún ejemplo, sin embargo, Kalaw refiere las lecturas de Dámaso Ponce sobre la representación en las Cortes, las de Pedro Serrano sobre las enseñanzas de los españoles, las de Rizal sobre el concepto de virtud, las de Del Pilar acerca del modo de contrarrestar el clericalismo. John Schumacher, "Philippine Masonry to 1890", Asian Studies 4, no. 2 (1966). 


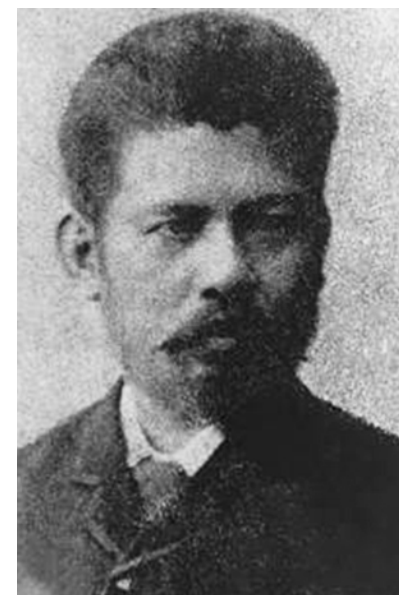

Marcelo Hilario Del Pilar

En este contexto de activa propaganda, Graciano López Jaena y el escritor y periodista Marcelo Hilario del Pilar, idean la creación de la Asociación Hispano-Filipina, sociedad teóricamente desvinculada de la masonería, cuyo fin era recabar apoyos de cualquier tipo para la causa filipina pero, sobre todo, para debilitar el poder del clero.

Sobre el momento de la fundación, estatutos, etc., no podemos apuntar gran cosa a excepción de que fue legalizada el 12 de julio de 1888, un año antes que el GOE, que lo fue el 7 de agosto de 1889 y que compartieron el mismo local de reunión. La Hispano-Filipina se definía a sí misma como una asociación «EMINENTEMENTE NACIONAL» $\sin$ «carácter político»:

Ajena a todo interés de partido y a todo exclusivismo de escuela y de secta religiosa, sólo aspira al mejoramiento material y moral del Archipiélago filipino, harto olvidado hasta el presente.

Acogerá en su seno a todos los españoles de buena voluntad que deseen ayudarla. Y se valdrá únicamente de la propaganda legal para influir en la opinión y conseguir de los Gobiernos y de las Cortes reformas administrativas y políticas en consonancia con las necesidades y estado social de nuestros hermanos del Archipiélago.

De esta suerte su lema será: Reformas para Filipinas ${ }^{15}$.

La presidencia de la asociación recayó en Miguel Morayta; como vicepresidente fue nombrado Dominador Gómez, y secretario Marcelo H. Del Pilar. Además estaba integrada por los miembros de la logia Solidaridad no. 53 y muchos de la Ibérica no. 7, ambas de Madrid. Los recursos económicos y materiales de la Asociación no fueron muchos, al menos en los primeros tiempos, finales de 1888, de ahí que recurrieran a la organización de frecuentes banquetes a los que eran invitadas destacadas personalidades de la vida pública, la política o la cultura, con el fin de dar mayor publicidad a sus actos. Con ese mismo objetivo nació a principios de 1889 el «quincenario democrático» La Solidaridad.
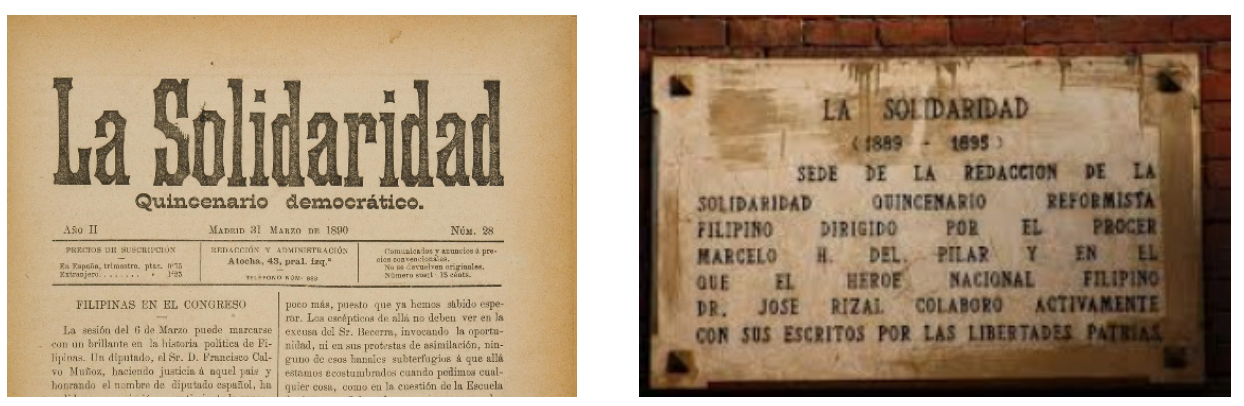

La vida de este periódico fue tan desconcertante como la de la asociación y la de la colonia

15 Boletín Oficial del Gran Oriente Español VIII, no. 114, 20 de septiembre de 1896, 206. 
filipina en general. Fue fundado por Marcelo H. Del Pilar, Graciano López Jaena y Mariano Ponce, y era financiado por el abogado filipino Pablo Rianzares. Tuvo su sede en Barcelona y salió a la luz el 15 de febrero de 1889. Su primer editor fue López Jaena, quien permaneció en ese puesto hasta noviembre del mismo año. Por problemas de salud se trasladó a Madrid, y con él, el periódico que, a partir de diciembre, cambió de director ${ }^{16}$. López Jaena cedió su puesto a Del Pilar, quien compaginaría las labores de Venerable de la logia Solidaridad no. 53 con las de editor del periódico, que ya no era de Rianzares, y las de la Asociación Hispano-Filipina.

Desde 1890 , la colonia filipina va a contar con tres foros en los que exponer y debatir sobre sus problemas: la logia Solidaridad y -por extensión- la masonería, la Asociación Hispano-Filipina y el periódico La Solidaridad. También en este periodo ya se advierte un cambio con respecto a la etapa anterior; la colonia asiática se muestra mucho más activa y radical. Las acciones emprendidas por dichas asociaciones durante este tiempo, en ocasiones, se funden y confunden; las demandas de los tres organismos, básicamente, eran tres: representación en las Cortes, abolición de la censura, lo que suponía una agresión directa contra las órdenes religiosas, y prohibición de las deportaciones arbitrarias.

Los años 1890 y 1891 fueron especialmente activos. En octubre de 1890 Morayta envió una circular a todas las logias dependientes del GOE, en la que abiertamente se mostraba el apoyo que esta obediencia prestaba a los filipinos en su campaña en pro de la representación en las Cortes. El 23 de diciembre de 1890, la Hispano-Filipina y la logia Solidaridad ofrecieron un banquete en honor del Hermano Manuel Becerra, Fortaleza, gr. $\cdot 33$ en agradecimiento por las disposiciones dictadas con respecto a las islas durante su mandato como ministro de Ultramar y que afectaban, básicamente, la mejora de la instrucción pública y la reducción de algunas atribuciones excepcionales de las órdenes religiosas.

Durante 1891 siguieron desarrollándose reuniones, asambleas y celebraciones, siempre con el mismo objetivo: conseguir la representación en las Cortes. Pero la campaña se vio sumida en una crisis debido a las diferencias de criterio entre Rizal y Del Pilar sobre la línea de actuación a seguir. A ello se sumó el desencanto porque sus pretensiones reformistas no se habían cumplido durante el gabinete de Sagasta y, ahora con Cánovas, se complicaban sus aspiraciones. Así las cosas, Rizal decide marcharse de España. Igual que él, salieron varios miembros de la Solidaridad no. 53 y de la asociación, algunos de los cuales regresaron a Filipinas con el permiso del GOE y el propósito firme de organizar y extender la masonería en las islas.

A partir de 1892, los datos sobre la campaña de los filipinos en la Península son menos abundantes. La logia Solidaridad no. 53 siguió abierta, pues se conserva documentación hasta septiembre de 1894, pero la Hispano-Filipina dejó de publicar el boletín de la asociación que aparecía inserto al final del periódico La Solidaridad. Por lo que respecta al periódico, tampoco sobrevivió mucho más. El último número es del 15 de noviembre de 1895, aunque no se había publicado desde septiembre de ese mismo año. Del Pilar y

$16 \quad$ La Solidaridad comenzó su andadura madrileña con el no. 19, el 15 de noviembre de 1889, teniendo su administración en la calle Monteleón no. 7. Del Pilar se lo había comprado a Rianzares y, a partir del no. 22, la administración se trasladó a la calle Atocha no. 43, domicilio de Del Pilar. Pero todavía cambiaría otra vez, desde el no. 65, del 15 de octubre de 1891, se localizó en la calle Rubio no. 13, también domicilio de su editor. 
Mariano Ponce se habían trasladado a Barcelona con la intención de regresar a Filipinas y continuar su activismo allí, pero Del Pilar nunca llegaría, pues falleció en julio de 1896 en la Ciudad Condal. Esta «huida» de los filipinos hacia su lugar de origen en 1892, coincide con la expansión de la masonería española en aquellas tierras y con la fundación de otras dos sociedades: la Liga Filipina y el Katipunan.

Las actividades de la Hispano-Filipina y de la Solidaridad no. 53, en gran medida, eran soportadas desde Manila, pero cuando los recursos fueron más útiles dentro de las islas que fuera, no dudaron en emplearlos y fueron poco a poco disminuyendo, hasta desaparecer. Fue la falta de financiación y de ayuda económica la que motivó la decadencia de las actividades de los filipinos en España ${ }^{17}$.

Resumiendo e intentando aclarar este conglomerado de sociedades y asociaciones, podemos afirmar que entre 1888-1889, tuvieron lugar los decisivos encuentros entre la colonia filipina peninsular y Morayta, y fue entonces cuando le instaron a que reformara los estatutos y reglamentos de su recién fundado Gran Oriente Español para que fueran admitidos los nativos en las logias. Morayta accedió, lo mismo que había accedido a presidir la Asociación Hispano-Filipina, porque consideraba que era un buen medio de debatir, siempre de acuerdo a la legalidad, las cuestiones y problemas que afectaban al lejano archipiélago, pero, en ningún momento, se planteó que podría llegar a tener problemas con las autoridades, como luego ocurriría.

Morayta defendía y apoyaba el asimilismo, la representación en las Cortes y una serie de reformas liberalizadoras que, dado su marcado carácter anticlerical, tendían a restringir la preponderancia de las órdenes religiosas. Algo que, perfectamente, podía haber sido el programa del Partido Asimilista de Filipinas, si este hubiera llegado a materializarse, como ocurrió en Cuba. Morayta nunca soportó ideas autonomistas y mucho menos separatistas, pero acabó convertido, casi más que Del Pilar y los otros, en -la cabeza visible de las aspiraciones filipinas debido a todos los trabajos realizados en el ámbito periodístico y en

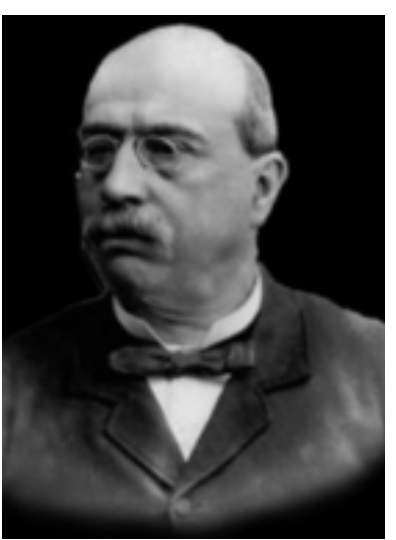

Miguel Morayta y Sagrario el del poder.

Todo esto nos lleva a pensar que la figura del Gran Maestre fue utilizada para prestigiar las acciones de Jaena y Del Pilar, quienes sí tenían planeado un doble juego. Jaena suscribía la intervención abierta de la masonería en la política y Del Pilar, aunque cara al exterior intentó mantener separadas las tres organizaciones ${ }^{18}$, siempre tuvo otro plan en su mente. Muestra de ello fue su negativa a que la colonia filipina de Madrid se agrupara en torno a la figura de Rizal, hombre más mesurado que él, alegando que no era necesaria esa organización: “¿2ué necesidad servirá esa organización? Para fines políticos dentro del marco de la legalidad tenemos la Asociación

17 La financiación tanto de la Asociación como del periódico no es del todo clara si bien todo apunta a que los fondos procedían del denominado Comité de Propaganda con sede en Hong Kong y al que pertenecían destacados personajes de la sociedad insular filipina, muchos de los cuales buscaron refugio en la colonia británica tras las condenas impuestas a algunos de ellos por la Revuelta de Cavite de 1872.

18 Hecho verdaderamente complicado pues como recordamos era venerable de la Solidaridad no. 53., secretario de la Hispano-Filipina y editor del quincenario La Solidaridad. 
Hispano-Filipina; para propósitos de propaganda, tenemos otro círculo a nuestra disposición con gran ayuda (la Masonería)" ${ }^{\text {. }}$. En estas palabras dirigidas a Deodato Arellano, uno de los fundadores del Katipunan, advertimos el verdadero fin de Del Pilar, que no era otro que utilizar la masonería como estructura organizada que era para servir a sus planes, a estas alturas, en perfecta conexión con la citada sociedad secreta.

Tras una década reivindicando pacíficas reformas, López Jaena cayó en el desánimo y fueron el cansancio y la frustración los que le condujeron a pensar en la violencia como única salida.

Por su parte desde que llegara a Madrid en 1888, Del Pilar mantuvo un estrecho contacto con Morayta porque, sin duda, necesitaba su apoyo incondicional a la campaña filipina, y los contactos que tenía en las altas esferas político-ideológicas españolas. Fue esa relación y lo que ella le podía reportar, lo que impulsó a Del Pilar a centralizar sus planes en la Península. Morayta, convencido de que lo que estaba promoviendo era justo, no dejaba de animar y dar nuevas ideas a los filipinos.

A partir de 1891 y una vez que Morayta autorizó la creación de logias del GOE en Filipinas, la relación entre el venerable de la Solidaridad y el Gran Maestre pareció enfriarse. Siguió habiendo apoyos y reconocimientos mutuos, pero ya no fueron las acaloradas campañas de los años precedentes. La institución se organizó en las islas bajo la dirección de fervientes nacionalistas que, a los pocos meses, decidirían utilizar su estructura organizativa para difundir ideas separatistas, dando lugar a la creación de una sociedad secreta a la que, ni mucho menos, pertenecieron todos los afiliados a la masonería.

Morayta no fue conocedor de estos actos, ni podía imaginarlos. La Solidaridad no. 53 había sido el puente entre España y Filipinas. La masonería había intervenido y apoyado la campaña asimilista filipina, pero no la nacionalista. Los planes separatistas de Del Pilar eran secretos, lo que convierte a este personaje en uno de los independentistas por excelencia, lo que ocurre es que, al haber fallecido en julio de 1896 y no vivir, exactamente, los acontecimientos de la insurrección contra España, su figura parece ser menos relevante, no equiparable a la de Emilio Aguinaldo o a la de Andrés Bonifacio, líderes katipuneros y cabecillas de los sublevados cuando, en realidad lo fue, tanto o más, que quienes se batieron en los campos filipinos. El doble juego de Del Pilar involucró a una institución entera, con todos sus afiliados, en algo a lo que era ajena y por lo que tuvo que pagar un elevado precio: la suspensión de trabajos y la acusación de traición.

\section{Nuevos órganos de acción}

Tras una larga estancia de Rizal en Europa, regresó a Filipinas en junio de 1892, previo paso por Hong Kong, importante foco de actividad nacionalista. Después de transcurrir unos ajetreados días de encuentros con propagandistas, entrevistas con el general Despujols y visitas a la familia, a comienzos de julio, Rizal presidió una reunión en casa del mestizo chino Teodoro Ongjunco, en Tondo ${ }^{20}$. El motivo de la reunión no era otro que constituir una nueva

19 Schumacher, "Philippine Masonry", 173.

20 Los asistentes a dicha convocatoria fueron: "Francés (propietario), Flores (teniente de Infantería), Rianzares (abogado), Zulueta 
asociación denominada Liga Filipina, a sabiendas de que era contraria a la ley del archipiélago y que, por tanto, tenía carácter secreto. El propósito de la liga era extender el reformismo por todas las islas: un reformismo basado en fomentar el adelanto y la cultura del país, propagar las ideas políticas avanzadas mediante conferencias, libros, folletos y estimular la creación de empresas e industrias. Acto seguido a la exposición del objetivo de la nueva sociedad, se dio lectura a un reglamento provisional, elaborado por el propio Rizal, que fue aprobado por unanimidad, si bien se modificaría después de ser estudiado a profundidad. Conocidos los hechos por el general Despujols, fueron la excusa perfecta para decidir deportar a Rizal y a otros líderes de la liga a Dapitan y Joló, respectivamente, consciente de lo comprometedora que era la estancia de ellos en Manila y lo peligrosa que era la nueva sociedad para la estabilidad de las islas.

La deportación disuadió al resto de los integrantes de la asociación mostrándoles lo complicado que podía ser acometer las pretendidas reformas, y el pacífico y dialogante grupo fue languideciendo hasta casi desaparecer. A comienzos de 1893 intentaron reanudarse los trabajos, unas veces en casa de Domingo Franco y otras en la de Deodato Arellano. Luego retomaron el reglamento de Rizal y tras votación, quedó constituido el Consejo Supremo de la Liga, con sede en Manila. Pero la liga no permaneció solo en las islas y se fundaron dos delegaciones, una en Hong Kong, presidida por Ildefonso Laurel, y la otra en Madrid, dirigida por Marcelo del Pilar.

La Liga Filipina, al igual que ocurriera con los anteriores órganos de acción, tampoco tuvo demasiada acogida en el resto de las provincias, de modo que en octubre de 1893, a la vista del lento progreso y del temor a ser descubiertos por las autoridades, hecho que ocasionaba constantes disidencias, se decidió disolverla. Para ello se convocó una asamblea en la que debían recogerse todos los documentos y, como si de un auto de fe se tratara, debían ser quemados. Algunos de sus miembros se refugiaron en la masonería, a estas alturas totalmente desvirtuada y alejada de sus principios, y otros formaron un comité para difundir y propagar las ideas y mantener vivo el espíritu de protesta.

Casi paralela a la fundación de la Liga Filipina tuvo lugar la del Kataastaasan Kagalanggalang na Katipunan ng Anak ng Bayan, más conocido como Katipunan o con sus iniciales K.K.K. Había llegado la hora de la acción. Pero la idea no era nueva. Ya en 1888 hubo un intento por parte del escultor Romualdo Teodoro de Jesús que, si bien en ese momento no fraguó, tampoco cayó en el olvido y, cuando cuatro años después, el 7 de julio de 1892 Despujols hizo público el destierro de Rizal al sur de Filipinas, se encendió la mecha para la creación de la nueva sociedad. Aunque en esta ocasión no sabemos quién fue el artífice de la propuesta, numerosos indicios apuntan a que fue Del Pilar desde España.

La organización de la nueva sociedad se asemejaba a la Liga Filipina, pero estaría inte-

(empleado), Adriano (notario), Reyes (sastre), Páez (agente de negocios), Francisco (industrial), Serrano (maestro), A. Salvador (contratista), Salazar (industrial), Mariano (propietario), Legazpi (industrial), José (propietario), Bonifacio (bodeguero), Plata (curial), Villarreal (sastre), Basa (tenedor de libros), Arellano (empleado militar), Ramos (industrial), Joven (propietario), Villarruel (comerciante), Mabini (abogado) Nacpil (platero) y otros muchos filipinos conocidos por sus ideas". AHNS., Leg. 219-A. 
grada por campesinos y gente sin ilustración dirigidos por los caciques y principales de sus pueblos y formarían un enorme grupo llamado a dar el grito de rebelión.

Con tal motivo se reunió en casa de Deodato Arellano (calle Azcárraga No. 72) un importante grupo de personas, entre los que figuraban varios exmiembros de la Liga Filipina, con el fin de organizar una sociedad que trabajara y luchara por librar a las islas del yugo español. Aunque hemos dicho que la organización del Katipunan era análoga a la de la liga, es importante no confundirlos, pues de pronto el espíritu reformista y dialogante de los anteriores había dado paso a una sociedad en la que se juraba odio y destrucción a todo lo que tuviera carácter español, a la vez que se sembraba el germen del odio racial. La organización era de tipo triangular, extendida por todas las islas, y para sus escasas comunicaciones escritas, inventaron un lenguaje secreto que tenía como base el tagalo. Todo esto quedó sellado, a la antigua usanza, mediante el pacto de sangre ${ }^{21}$.

En estos avatares, las logias, desvirtuadas y anuladas, van a ser utilizadas como vía de expansión de las ideas autonomistas e independentistas de una sociedad secreta revolucionaria denominada Katipunan, cuyos principios distaban mucho de los de la masonería.

Desaparecida la masonería de Filipinas oficialmente el 21 de agosto de 1896, tras su inculpación en la revuelta Katipunera y en la posterior pérdida de las colonias ultramarinas, la institución se sumió en un profundo letargo. La clausura de las logias, la incautación de archivos, registros y bienes junto con la persecución de sus integrantes, la condujeron a la inactividad, a la vez que comenzó a forjarse la leyenda negra que convertiría a la masonería en una fuerza oculta capaz de provocar revoluciones.

Pero a pesar del alto precio que tuvo que pagar, la masonería española del siglo XIX había dejado una huella imborrable en Filipinas y sus destinos permanecieron unidos durante mucho más tiempo. Regresó la institución a suelo filipino en 1899, pero bajo otras condiciones. Ahora fueron los filipinos quienes se organizaron bajo la única obediencia que superó la crisis finisecular, el Gran Oriente Español, prefiriendo, además, depender de España antes que hacerlo de su nuevo colonizador, Estados Unidos. Este hecho trajo consigo no pocos enfrentamientos entre ambas masonerías, española y estadounidense, por problemas jurisdiccionales de territorialidad masónica.

Durante este nuevo período, una vez que la vorágine de la insurrección había pasado y la

$21 \quad$ Sobre este ritual se ha especulado mucho y, en realidad, no obedecía sino a una antigua costumbre prehispánica. Como explica Retana en su Diccionario de Filipinismos, pacto de sangre es la ceremonia de sangrarse. "Con esta frase han sustituido algunos escritores modernos la antigua palabra sangrarse. Sirvió de título al pintor ilocano Juan Luna para el cuadro que representa las paces pactadas entre el conquistador Legazpi y el reyezuelo Sicatuna".

Vestigio de la antigua bárbara costumbre de sangrarse se debe reputar el juramento de los afiliados al Katipunan (1892-1896); los cuales suscribían su compromiso mojando la pluma en la sangre que les brotaba de la incisión que, al efecto, se hacía cada conjurado al tiempo de firmar: "Los antiguos filipinos tenían varios modos de jurar solemnemente sus pactos: uno de ellos, sin duda el más clásico y generalizado de todos, consistía en sangrarse. Los contratantes se producían una herida (de ordinario en el brazo), cuya sangre depositaban en un pequeño receptáculo; y hecho esto, cada uno se bebía la sangre del otro... Miguel López de Legazpi, conquistador de Filipinas, conocedor de la costumbre de sangrarse, no vaciló en hacerlo con Sicatuna, régulo de Bohol, en su deseo de conseguir por medios pacíficos el fin que perseguía”. Retana, Diccionario de Filipinismos, 137 y 160. 
pasión revolucionaria se había encauzado por el sendero de la legalidad, los filipinos y la masonería española a la que se afiliaron mayoritariamente, enarbolaron la bandera de la hispanidad ensalzando su pasado colonial español y en especial su idioma como principal baluarte frente a la americanización. En España y con su lengua habían sido educados los primeros nacionalistas y se difundieron las ideas de dignificación de la raza y de solidaridad nacional que condujeron al deseo de una existencia independiente. En español fue declarada la República de Filipinas por Emilio Aguinaldo; en la misma lengua fue escrita la Constitución de Malolos promulgada el 22 de enero de 1899; en español fue compuesto el himno nacional de Filipinas, cuya letra y música corrieron a cargo de dos miembros de la masonería española, Mariano y Remigio Jocsón, respectivamente, ambos pertenecientes a la logia Nilad no.144 de Binondo (Manila).

\section{Conclusión}

Los estudios sobre movimientos sociales y asociativos, sociología de grupo, psicología social, y otras disciplinas parecidas han proliferado y se han desarrollado mucho en los últimos años, de tal modo que podemos sentir la necesidad de acercarnos a estudios históricos de grupos desde estas perspectivas; sin embargo, no debemos caer en el error de analizar comportamientos ocurridos hace más de un siglo desde la óptica actual y con metodologías del siglo XXI.

En los diferentes movimientos asociativos por los que atravesó la masonería española en Filipinas, apreciamos distintos intereses de agrupación aunque todos tendentes a un mismo fin, conseguir reformas en las islas para las obsoletas estructuras de la administración española. Y en todo el proceso evolutivo, se observan niveles que van desde la simple exposición de demandas durante el periodo peninsular, a su traslación a una estructura económico-social y cultural determinada ya en Filipinas, que desencadena los acontecimientos.

Antes de llegar al levantamiento anticolonial contra España hubo numerosas formas de movilización intelectual y popular, cada una manifestada en un tipo de asociación y vinculación con metodología, ámbito de actuación, integrantes e intereses diferentes. Por medio de estas agrupaciones se puede ir observando el progresivo cambio de actitud que condujo al levantamiento de 1896, al denominado Grito de Balintawak ${ }^{22}$.

Es de destacar que no hubo una gran participación en ninguna de las actividades asociativas legales que se fueron sucediendo $0^{23}$. Indudablemente existía un escollo difícil de superar, cual era el del sustento económico. Todas las asociaciones necesitan financiación, máxime cuando están tan alejadas de su centro de acción, como ocurría entre Filipinas y España; sin embargo, en este caso trataron de suplirlo con otros intereses. Enfatizaron valores como la dignidad, la igualdad y la autonomía de las personas y las encaminaron a conseguir una mayor participación en una pretendida sociedad laica, desligada de la influencia del clero. Se dio gran importancia a la comunicación y a la información, haciendo especial hincapié en la libertad de expresión y la defensa de los derechos civiles. Los medios de comunicación adquirieron un papel preponderante mediante el cual se dieron a conocer las presiones económicas y las

\footnotetext{
22 El 23 de agosto de 1896 los líderes del Katipunan, a la cabeza de ellos Andrés Bonifacio, se alzan en armas contra España al grito de ¡Viva Filipinas! y ¡Viva el Katipunan!. Este hecho es conocido como Grito de Balintawak.

23 Obviamente excluimos la organización y el reclutamiento de adeptos al Katipunan puesto que ni sus actividades eran lícitas, ni se trata de una organización vinculada a la masonería.
} 
desigualdades sociales; además, se desafió a las autoridades en aspectos políticos y culturales defendiendo la representación en las Cortes y la cultura ancestral frente a la imposición administrativa.

La historia de la institución masónica en España es la historia de sus defensores y de sus detractores, no habiendo estudios serios, científicos y críticos hasta hace tres décadas. Por este motivo, al acercarnos a una obra que trate sobre masonería durante la segunda mitad del siglo XIX, hemos de tener muy presente, como explica el profesor Ferrer Benimeli, la época, la ideología y la profesión del autor para determinar su valor real ${ }^{24}$.

Así, desde el ámbito académico se deben seguir fomentando estudios veraces, documentados y contrastados, a fin de desmitificar esa historia con minúscula contada, repetida y extendida como veraz pero que, en realidad, no obedece sino a modas y tendencias.

24 Ferrer Benimeli, Masonería española contemporánea (Madrid: Siglo XXI, 1986). 


\section{Fuentes}

A lo largo de este trabajo se han referenciado dos legajos de documentos del actual Centro Documental de la Memoria Histórica (CDMH) sito en Salamanca, que hemos querido conservar con la nomenclatura con la que fueron consultados en su momento y por la que siguen siendo localizables:

Archivo Histórico Nacional Salamanca (AHNS), Leg. 736-A-11 y Leg. 219-A.

\section{Bibliografía}

Adán Guanter, Manuel. "Una logia de filipinos en Madrid: Solidaridad no. 53 (1889-1895)". En La masonería en la España del siglo XIX. Coordinado por José Antonio Ferrer Benimeli. Valladolid: Junta de Castilla y León, 1987.

Boletín Oficial del Gran Oriente Español. Año VIII, no. 114, 20 de septiembre de 1896.

Cabrero, Leoncio. "La actitud de la masonería ante la independencia de Filipinas". En Masonería española y América. Coordinado por José Antonio Ferrer Benimeli. Zaragoza: CEHME, 1993.

Cuartero Escobés, Susana. "Fuentes para el estudio de la masonería española en Filipinas". En Masonería española, entre Europa y América. Coordinado por José Antonio Ferrer Benimeli. Zaragoza: CEHME, 1994.

Cuartero Escobés, Susana. "El nacionalismo independentista del Katipunan". En Antes del “desastre:" Orígenes y antecedentes de la crisis del 98, Madrid: Universidad Complutense, 1996.

Cuartero Escobés, Susana. "Spanish Masonry in the Philippines". En Unknown Aspects of the Philippine Revolution. Editado por Fr. José Arcilla. Manila: St. Pauls, 2006.

Ferrer Benimeli, José Antonio. Masonería española contemporánea. Madrid: Siglo XXI, 1986.

Ferrer Benimeli, José Antonio. "Implantación de logias y distribución geográfico-histórica de la masonería española”. En La masonería en la España del siglo XIX. Coordinado por José Antonio Ferrer Benimeli. Valladolid: Junta de Castilla y León, 1987.

Ferrer Benimeli, José Antonio, y Susana Cuartero Escobés. "José Rizal y la masonería en el centenario de su fusilamiento" (1896-1996)”. En Aragón y la crisis colonial de 1898. Zaragoza: Diputación General de Aragón, 1999.

García Barzanallana, M. La masonización de Filipinas. Rizal y su obra. Barcelona: Librería y Tipografía católica, 1897. 
Ortiz Armengol, Pedro. "Fuentes históricas filipinas sobre Rizal y su entorno". En La Masonería española y la crisis colonial del 98. Coordinado por José Antonio Ferrer Benimeli. Zaragoza, CEHME, 1999.

Pérez López, Pablo. "Masonería e insurrección en Filipinas en la publicista de la época". En Masonería española y América. Coordinado por José Antonio Ferrer Benimeli. Zaragoza: CEHME, 1993.

Retana, Wenceslao E. Archivo del bibliófilo filipino. Recopilación de documentos históricos, científicos, literarios y políticos. Madrid: Imprenta de M. Minuesa de los Ríos, 1905.

Retana, Wenceslao E. Diccionario de filipinismos: con la revisión de lo que al respecto lleva publicado la Real Academia Española. New York: Imprenta de la casa editorial Bailly-Baillière, 1921.

Sánchez Ferré, Pere. "La masonería española y el conflicto colonial filipino". En La Masonería en la España del siglo XIX, Coordinado por José Antonio Ferrer Benimeli. Valladolid: Junta de Castilla y León, 1987.

Sánchez Ferré, Pere. "Nacionalismo y masonería en España (1880-1939)”. Cuadernos de Investigación Histórica Brocar 17 (diciembre 1991): 71-84.

Schumacher, John. "Philippine Masonry to 1890". Asian Studies 4, no. 2 (August 1966).

Schumacher, John. "Filipino Masonry in Madrid. 1889-1896". Philippine Historical Review 1 (1966): 168-182. 